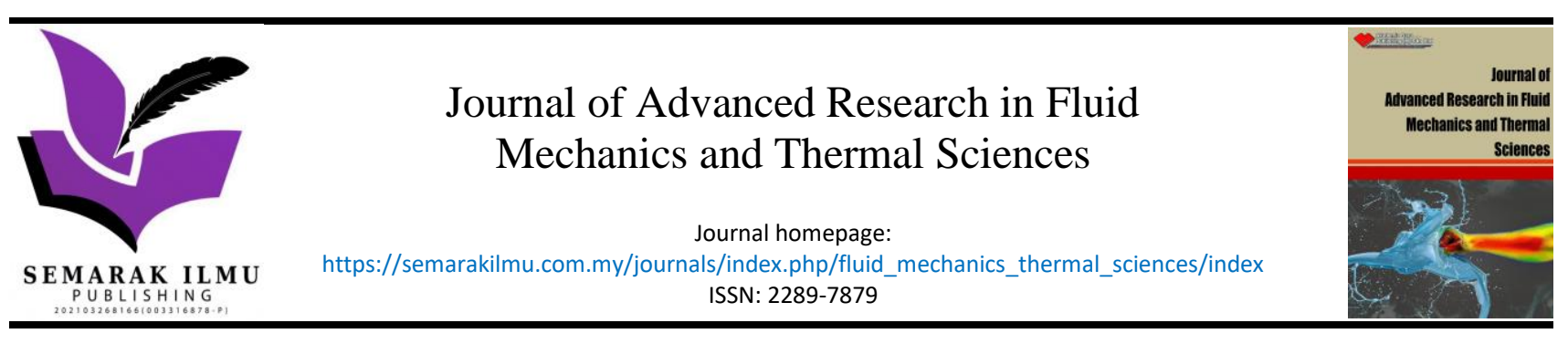

\title{
Simulation of the Conical Gravitational Water Vortex Turbine (GWVT) Design in Producing Optimum Force for Energy Production
}

\author{
Muhammad Qamaran Abdul Aziz ${ }^{1,2,3}$, Juferi Idris ${ }^{1,2, *}$, Muhammad Firdaus Abdullah ${ }^{3}$ \\ 1 Faculty of Chemical Engineering, College of Engineering, Universiti Teknologi MARA (UiTM), Sarawak Branch, Samarahan Campus, 94300 Kota \\ Samarahan, Sarawak, Malaysia \\ Faculty of Chemical Engineering, College of Engineering, Universiti Teknologi MARA (UiTM), 40450 Shah Alam, Selangor, Malaysia \\ Stoma Sdn Bhd, 387, Sub Lot 28, Lorong Burung Bunga Api, Taman Hong Leong, Jalan Penrissen, 93250 Kuching, Sarawak, Malaysia
}

\section{ARTICLE INFO}

\section{Article history:}

Received 31 August 2021

Received in revised form 21 October 2021

Accepted 3 November 2021

Available online 30 November 2021

Keywords:

Gravitational water vortex turbine; conical; turbine orientation

\section{ABSTRACT}

Sustainable electricity power supply is crucial especially for less populated rural area. Micro hydropower generation in rural area is important in providing electricity especially in off-grid electricity area. This study aims to predict and harness power from micro hydropower generation through conical gravitational water vortex turbine (GWVT) via SOLIDWORKS flow simulation. Conical GWVT under study was designed as fully enclosed system with conical turbine basin. Two different turbine orientations were simulated i.e., vertical and horizontal at different blade angle designs i.e., $25^{\circ}, 45^{\circ}, 75^{\circ}, 90^{\circ}$, and $120^{\circ}$ and with different number of blades i.e., 8,12 , and 18 while forces were harnessed at tangential ( $z$-axis) direction. The simulation results showed that it was possible to run and produce force from conical GWVT design in a fully enclosed system. It was found that vertical turbine orientation produced a slightly higher force than horizontally orientated turbine, using 12 runner blades at $90^{\circ}$ angles where the distributed forces were $15.31 \mathrm{~N}$ and $14.12 \mathrm{~N}$ respectively, at tangential (z-axis) direction. The results are useful to predict turbine's torque for small capacity micro hydropower electricity generation prior to actual conical GWVT set up, in rural area, to minimise cost implication and construction issues.

\section{Introduction}

Progress in economy of a country is highly influenced by developments in sustainable energy supply as part of their macroeconomics approach [1]. Power source attribution in Malaysia was found to be $88.4 \%$ from fossil fuel and $11.4 \%$ from hydropower [2]. This shows that Malaysia still heavily relies on conventional fossil fuel resources as their main power source. As a fast-developing country, it seems synonymous to observe the energy demand increases in parallel with the country's developments. Presently in Malaysia, electricity generation capacity installed is $\mathbf{3 0}$ gigawatt and the monthly average electricity demand is kept at maximum 17,000 megawatt, also known as the demand barrier [3].

\footnotetext{
* Corresponding author.

E-mail address: juferi@uitm.edu.my
}

https://doi.org/10.37934/arfmts.89.2.99113 
Issues on the lack of rural electrification in Malaysia, especially in Sarawak and Sabah are yet to be fully resolved. Virtually, as observed through image segmentation and regional technique, about 1623 locations in Sarawak had to settle without electricity [4]. The fraction of electricity coverage in rural areas of Sarawak and Sabah is around 79\% compared to $99.62 \%$ in Peninsular Malaysia [5]. From the tens of thousands of schools in Malaysia, 809 of them are still not equipped with on-grid electricity supply and most of the power supply are from diesel generators, mostly in Sarawak and Sabah. If the power connection is not immediately resolved, the problem may persist for another five to ten years times [6]. Sarawak holds roughly 2.77 million population and made up $40 \%$ of Malaysia's land, about 124,450 km² in 2017 according to Department of Statistics Malaysia (DOSM) [7]. The state of Sarawak has 1.1 million people living in the rural areas. From the study by Khengwee et al., [8], the number of households not having electricity access for a continuous 24 hours per day in 2014 to 2016 was estimated at 41,004 .

Recent studies indicate mini hydros are the most promising efficient renewable energy approach in Malaysia compared to wind energy [9]. With the abundance of renewable energy resources in Malaysia, a hybrid system is a likely candidate for electrification in off-grid rural areas [10]. Up to now, nearly 300 rural settlements in Sarawak are supplied by solar-diesel hybrid mini-grids, solar home systems or mini-hydro power plants [11]. Renewable energy is an element of limitless source and some of the major examples are wind, solar, biomass, hydropower, and tidal energies [12]. Among these energy sources, hydropower is considered as having a high potential in Malaysia as the country is rich with flowing rivers, about 50 of them are in Sabah and Sarawak and 150 in Peninsular Malaysia [13]. Sarawak being the largest state in Malaysia is blessed with a coastline stretching over $800 \mathrm{~km}$ throughout the northwest coast of Borneo [14]. The abundance of rivers gave rise to potential electricity generation especially micro hydropower installations for rural areas. There is a total of 149 potential micro hydropower in Malaysia at $50 \mathrm{~m}$ head and above [15]. In Sabah and Sarawak, the potential of micro hydropower for $3182 \mathrm{~kW}$ and $6317 \mathrm{~kW}$ power supply were studied at 18 and 22 sites, respectively [5]. Sarawak's river abundance provides good opportunity for micro hydropower setup at 22 potential sites [15]. Thus, a study on hydropower turbine could aid the state to properly harness the energy from the natural resources.

Turbines are classified into impulse and reaction turbine. Enclosed type turbine is called reaction turbine, usually achieved through a pressure casing [16]. Power is generated from the mutual action of water trajectory and pressure. Francis turbine is one of the most prominent reaction turbines [17]. This turbine is designed with radial flow runner and some are equipped with a mix of axial flow runner in maximising energy harness [18]. The hydraulic efficiency of Francis turbine can reach $96 \%$ at their best operating point [19]. However, the efficiency drops in off-design conditions are mostly due to inlet's incidence losses or spin losses from outlet, etc.

The gravitational water vortex turbine (GWVT) design is a type of micro hydro turbine that falls under the impulse turbine category [20] where it involves an artificially induced free surface vortex (FSV) [17]. The basic operating principle of this turbine is that energy is harnessed from a free vortex developed in the centre of the basin. The vortex is created by introducing water tangentially into a circular basin with an orifice outlet positioned in the centre [21]. Energy is then harvested from the vortex by the turbine's runner [22]. It operates through axial shaft just like the Kaplan turbine by utilizing the swirl flow to produce power [23]. GWVT is classified as a micro hydro turbine as its power output does not exceed $100 \mathrm{~kW}$ [24]. An illustration of cylindrical GWVT design taken from a review by Rahman et al., [22] and conical GWVT design is illustrated in Figure 1 below [25]. 


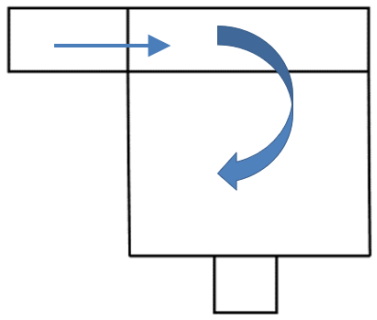

(a) Cylindrical Casing

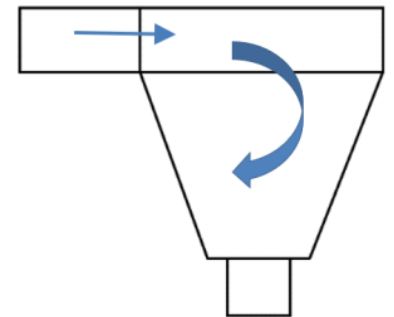

(b) Conical Casing

Fig. 1. The conventional GWVT operates by introducing free surface vortex flow via open channel tangentially into the turbine casing/basin, where there are two types of design a) Cylindrical and b) Conical GWVT design

Conventional GWVT design calls for free surface vortex as its inlet requirement which confines the turbine operation to be mostly in upright position [17]. Nonetheless, a penstock inlet design may provide higher efficiency to the turbine by understanding the core requirements of inlet such as matching nozzle with runner design for efficient conversion of head to kinetic energy [26]. A crossflow turbine, for example, depends on nozzle entry arc to maximise its tangential velocity towards runner blade [27]. Thus, blade configuration is essential in harnessing power from water flow. Besides blade design, other blade configurations such as blade angle and number of blades are important in influencing its efficiency in extracting power from the water flow. Some internal parameters such as the vortex angle at blade's inlet and relative flow angle at blade's exit are inter-related [28]. As the number of blade increases, the rotational velocity decreases, thus increasing axial velocity of water and ultimately reducing turbine's efficiency [28]. The study by Sritram and Suntivarakorn [29] in 2019 tested different number of blades ranging from 2 to 7 and found that 5 blades produced the highest torque as it provides the best distance between blades for her GWVT setting. In a mixed flow turbine, one of the most important attributes to take into account is the tangential velocity of the flow which can be converted into mechanical energy [30]. A runner blade produces torque via tangential force acting upon it which is needed to produce power [31]. Torque is considered one of the key performance parameters in analysing a turbine [32]. Thus, identifying tangential force in determining possible torque outcome is crucial.

Sritram and Suntivarakorn [33] found out that efficiency of cylindrical GWVT was better than using undershot water wheel under the same inlet conditions. Meanwhile, conical GWVT designed by Dhakal et al., [34] produced higher efficiency compared to cylindrical GWVT when both designs are in upright orientation however carried out a study on enclosed GWVT using a cylindrical basin design and found that horizontal operation is feasible [35]. The turbine was designed to harness power from the river flow. Three types of runner blades were tested namely Michel-Banki, single helical and double helical runner blades where the Michel- Banki runner blade produced the best power output, tested at $0.079 \mathrm{~m}^{3} / \mathrm{s}, 0.087 \mathrm{~m}^{3} / \mathrm{s}$ and $0.102 \mathrm{~m}^{3} / \mathrm{s}$ of flowrate. The blade configuration in terms of design was tested to identify best power output. Therefore, this study proposes to simulate GWVT turbine using conical design with different runner blade numbers and angles.

Computational Fluid Dynamic (CFD) can be carried out using different types of software to study fluid flow and one of them is SOLIDWORKS Flow Simulation [36]. The SOLIDWORKS Flow Simulation applies Navier-Stokes equations in their solver, which are derived formulation from momentum, mass and energy conservation laws [37]. The lack of simulation study done prior to the actual turbine fabrication have seen complex high internal and external resistance arise. Furthermore, ZarateOrrego et al., [35] also suggested that the aid of numerical simulation can improve vortex flow. Thus, a simulation study on enclosed GWVT using SOLIDWORKS Flow Simulation is one of the possible methods used in observing the flow trends inside the turbine and calculating the force harnessed by 
the runner blades. SOLIDWORKS Flow Simulation can calculate both laminar and turbulent flow problems. As turbulence flow has a random and inconsistent nature, to estimate turbulent flows SOLIDWORKS Flow Simulation uses Favre-averaged Navier-Stokes equations where time-averaged effects towards flow turbulence (flow parameters) are considered. By using this method, terms such as Reynolds stresses appear in the equations. This requires additional information to be provided. SOLIDWORKS Flow Simulation uses transport equations associated with turbulent kinetic energy and its dissipation rate, using the $k-\varepsilon$ mode [37].

Based on the studies mentioned, there is a limited study focussing on GWVT design in fully enclosed system with conical basin. Therefore, the potential of force produced using GWVT design in fully enclosed system with conical basin will be simulated and studied using SOLIDWORKS flow simulation. A CFD analysis using SOLIDWORKS Flow Simulation package will be used during this study to predict the force distribution and power produced from the turbine. The novel design calculation is mainly based on a conical body design following GWVT rule of thumb to be 0.3 of outer diameter and operating principle of Francis turbine where flow enters in a radial manner. Thus, this study aims to simulate the conical GWVT in a fully enclosed system as reaction turbine for efficient force production with different parameter manipulated i.e., turbine orientation, blade angles design, and number of blades. The best design and configuration produced are crucial to better understand the actual set up of GWVT in minimising the cost and implied problems.

\section{Numerical Setup}

The proposed simulation design of the turbine in this study was based on conical GWVT where unlike other GWVTs, this system was modified and done as a fully enclosed system. The selected inlet design is $0.057 \mathrm{~m}$ diameter pipe without nozzle. Since the runner blade design is yet to be optimised, the selection of inlet pipe is based on general penstock diameter at $0.057 \mathrm{~m}$. The conical design was based on 0.3 diameter (0.3D) ratio of the total diameter as suggested by Sreerag et al., (2016). This version of modified conical GWVT, unlike the conventional GWVT, allows it to operate in both upright and horizontal positions. This is important to identify which orientation will produce more force during simulation before carrying out further analysis. The force measured in this simulation was based on 12 blades design and positioned at different blade angles i.e., $25^{\circ}, 45^{\circ}, 75^{\circ}, 90^{\circ}$, and $120^{\circ}$. After the optimum produced force using the best blade angle was identified, the force calculation was further simulated using different number of blades i.e., 8 and 18 blades. In this study, only force at tangential direction (Z-axis) was calculated. Prior to simulation, processor e.g., meshing, computational domain setting, goals identification as well as detailed turbine geometry, and blade angle specifications were conducted, with the explanation as follows.

\subsection{Pre-Processor Settings}

The CFD software used in this study was SOLIDWORKS Flow Simulation software. Flow simulation is an additional plug in for the SOLIDWORKS software. Firstly, in the project wizard, internal analysis was selected since the fluid flow was located inside the geometry. Water was selected as the operating fluid in the pre-processor. Then, the k-epsilon model was selected as the turbulence model as it was suitable for identifying the effects on a surface. Finally, flowrate was set at $0.01 \mathrm{~m}^{3} / \mathrm{s}$ throughout the study. The head of the turbine was identified by converting inlet pressure to head which is $10.5 \mathrm{~m}$. The details of the turbine boundary condition are explained in turbine geometry specifications in Section 2.2. 
The consistency of the results was optimized by refining the grid size. A grid independent test was carried out to identify the best possible grid size to ensure consistent simulation results where the grid number tested were up to 227,478 .

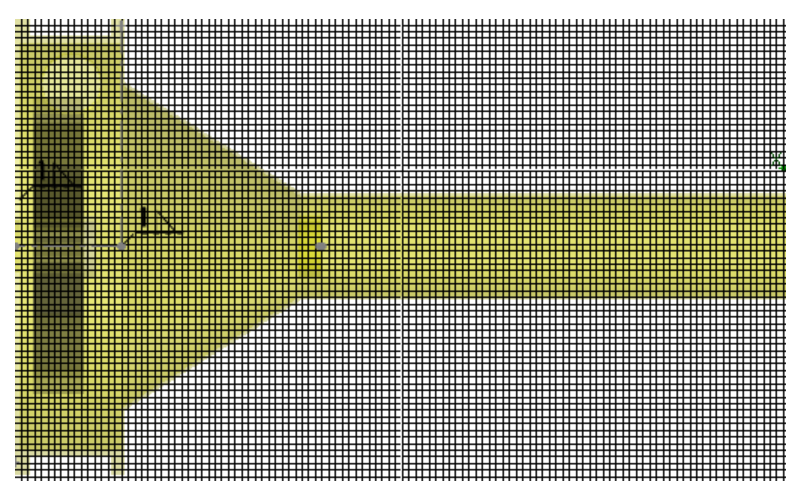

Fig. 2. Global meshing display of turbine by

Cartesian meshing

The computational domain was then positioned to a location of study in the turbine i.e., inlet, penstock, turbine casing, blade angle, and outlet. After all the relevant parts have been identified, the border of the computational domain was then defined as shown in Figure 3 . This is to resolve the pressure and velocity concerns at each part of the domain.

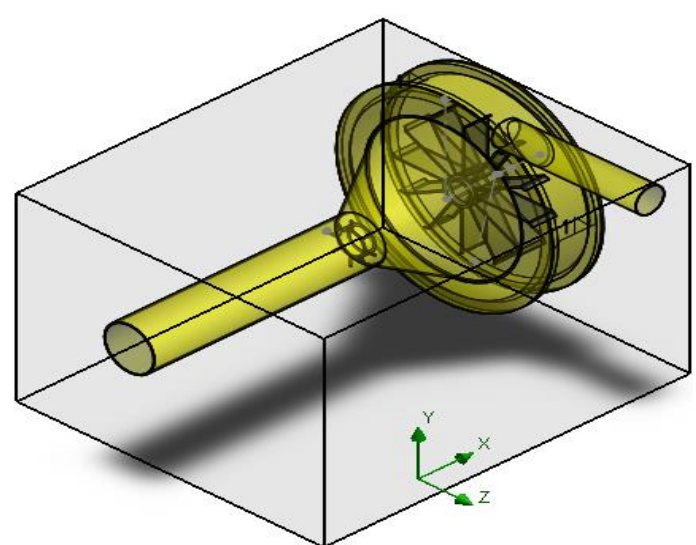

Fig. 3. Computational domain of interest resized to encapsulate turbine

In this SOLIDWORKS framework, it is important to specify the global goals (GG) and surface goals (SG) to ensure the solver will calculate the targeted parameters at the end of the calculation. The GG was set for average total pressure and average total velocity. The surface goal (SG) set was force, where the forces were at $X, Y$, and Z-axis. Total force was chosen as the parameter to run Grid Independent Test and force at Z-axis (tangential force) for the analysis. The setting of GG and SG which were specified in the solver is shown in Figure 4. It is important to minimise the number goals to suit the study's relevant parameters only so that we can reduce computational time taken. 


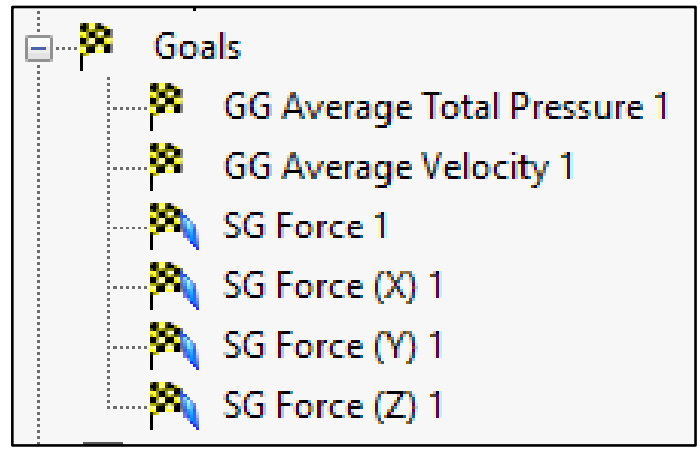

Fig. 4. Global goals (GG) and Specified Goals (SG) selected in the solver

\subsection{Turbine Geometry Specifications}

There were 9 main components of the turbine as specified in Figure 5. The detailed turbine geometry design specification is as stipulated in Table 1.

The size and dimension setup were chosen to meet a $10 \mathrm{~kW}$ size turbine while being paired to a low speed permanent-magnetic synchronous generator (PMG) [38].

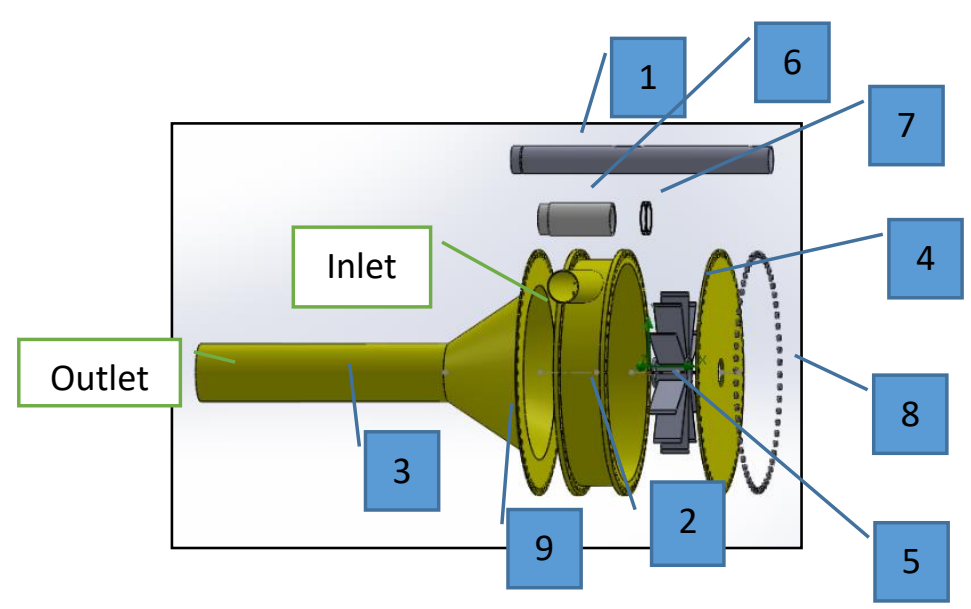

Fig. 5. Schematic diagram of GWVT with numbered labels

\section{Table 1}

Turbine geometry specification

\begin{tabular}{|c|c|c|c|c|c|}
\hline Item No. & Parts & Specifications & Item No. & Parts & Specifications \\
\hline 1 & Shaft & $\begin{array}{l}L_{\text {shaft }}=500 \mathrm{~mm} \\
\emptyset_{\text {shaft }}=50 \mathrm{~mm}\end{array}$ & 6 & $\begin{array}{l}\text { Long Sleeve } \\
\text { (Discharge side) }\end{array}$ & $\begin{array}{l}\emptyset_{\mathrm{s} 1}=50 \mathrm{~mm} \\
\mathrm{~L}_{\mathrm{s} 1}=140 \mathrm{~mm}\end{array}$ \\
\hline 2 & Inlet & $\varnothing_{\text {inlet }}=57 \mathrm{~mm}$ & 7 & $\begin{array}{l}\text { Short Sleeve } \\
\text { (Motorside) }\end{array}$ & $\begin{array}{l}\emptyset_{\text {inner }}=50 \mathrm{~mm} \\
\mathrm{Ls}_{\mathrm{s} 2}=10 \mathrm{~mm}\end{array}$ \\
\hline 3 & $\begin{array}{l}\text { Draft tube } \\
\text { (outlet) }\end{array}$ & $\varnothing_{\text {outlet }}=100 \mathrm{~mm}$ & 8 & Bolts & $\emptyset_{\text {bolt }}=10 \mathrm{~mm}$ \\
\hline 4 & $\begin{array}{l}\text { Motorside } \\
\text { Cover }\end{array}$ & $\emptyset_{\text {motor }}=450 \mathrm{~mm}$ & 9 & Cone Body & $\emptyset_{\text {cone }}=330 \mathrm{~mm}$ \\
\hline 5 & Runner & $\emptyset_{\mathrm{RB}}=280 \mathrm{~mm}$ & & & \\
\hline
\end{tabular}




\subsection{Turbine Orientation}

Figure 6 shows two orientations of the turbine which are a) vertical and b) horizontal to be tested in the simulation. The orientation of the turbine is significant to ensure actual setup will be feasible for implementation. For vertical orientation, the gravity of the CFD analysis will be at $(+X)$ direction while horizontally the gravity will be at $(-Y)$ direction. The optimum force produced is when the fluid acts towards blade. The blade was fitted into a $50 \mathrm{~mm}$ shaft before being connected to the motor so that the movement of the blade is converted to mechanical shaft rotation.

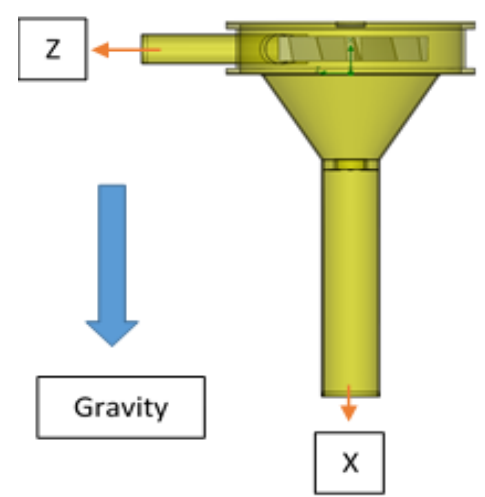

(a) Vertical orientation

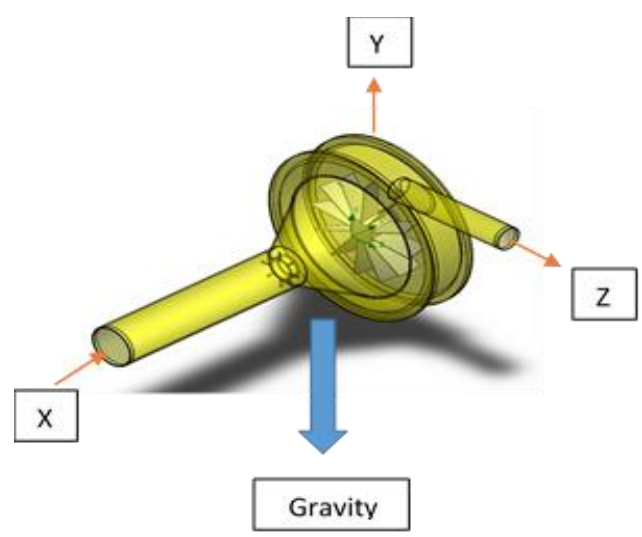

(b) Horizontal orientation

Fig. 6. Two orientations of the turbine categorized as a) Vertical and b) Horizontal orientation Blade Angle Specification

\subsection{Blade Angle Specification}

Figure 7 shows five schematic diagrams of rectangular blade designs and their detailed specifications are as stipulated in Table 2 . Twelve blades were used in this simulation at different angles of $25^{\circ}, 45^{\circ}, 75^{\circ}, 90^{\circ}$, and $120^{\circ}$. The runner blade was placed below the mouth of inlet which is located $50 \mathrm{~mm}$ from the turbine flat lid. The blade was axially located in the centre of the turbine.
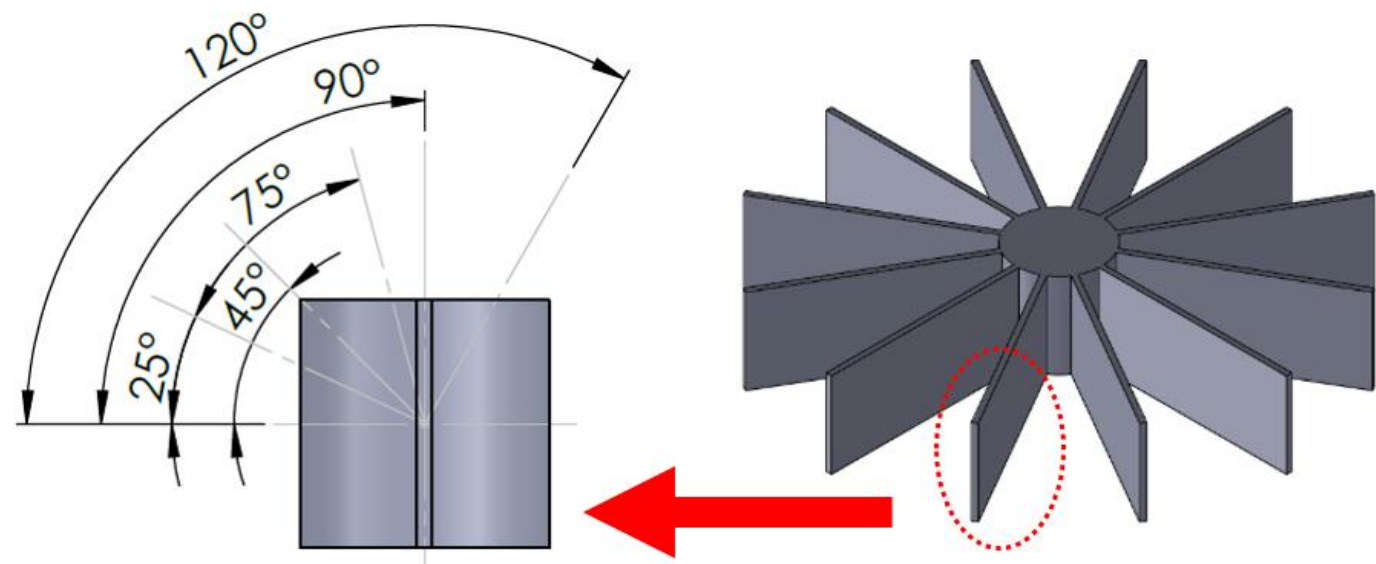

Fig. 7. Runner blade angles designed at angles of $25^{\circ}, 45^{\circ}, 75^{\circ}, 90^{\circ}$ and $120^{\circ}$ 
Table 2

Specifications of runner blade angle

\begin{tabular}{ll}
\hline Item & Specification \\
\hline Runner Blade diameter & $280 \mathrm{~mm}$ \\
Runner Blade width & $50 \mathrm{~mm}$ \\
Runner Blade Angle, $\alpha$ & $25^{\circ}, 45^{\circ}, 75^{\circ}, 90^{\circ}$ and $120^{\circ}$ \\
Number of blades, $\mathrm{Z}$ & 12 \\
\hline
\end{tabular}

\subsection{Number of Blades}

Figure 8 shows three different number of blades used in this simulation i.e., 8 and 18 blades, tested after using 12 blades. The number of blades is important to identify possible output force produced when in contact with water from inlet section. Blade numbers affect the blade gap between each blade; thus, it is crucial to know the best number of blades which can produce the largest surface area of contact when water enters the turbine. As the number of blade increases, the gap between each blade decreases.

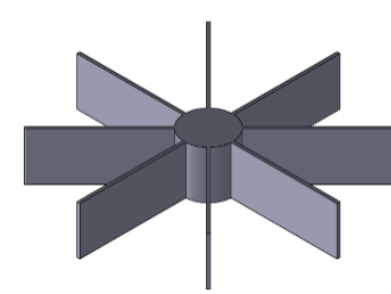

(a)

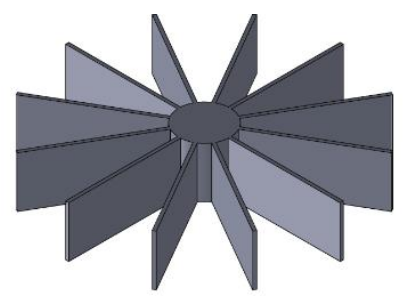

(b)

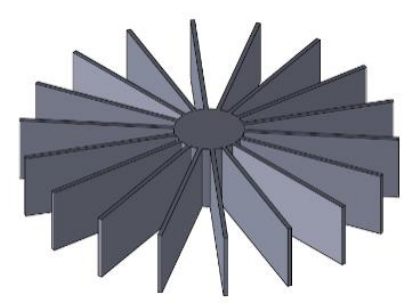

(c)

Fig. 8. Two number of blades design a) 8 blades, b) 12 blades and c) 18 blades

\subsection{Data Analysis (Post-Processing)}

After running the simulation, SOLIDWORKS Flow Simulation is able to come out with converged data such as force, velocity and pressure results. This result is further supported with visual results like velocity contour and flow trajectory for us to understand the pattern of water flow inside the casing of the turbine and reactions as it come in contact with runner blade. The data analysis process is consistently used in determining optimum turbine orientation, runner blade angle and number of runner blades which produced highest force as discussed in Section 3.

\section{Results and Discussion}

The consistency of the results was determined through a series of repeated tests to determine accurate settings prior to the experimental simulation on turbine orientation and number of blades. Each result is visualised through cut plot of flow velocity.

\subsection{Meshing Analysis}

Figure 9 shows the grid independent test which identified 113,273 grids as the best result able to stabilise with respect to the force results at 227,478 grids. There were minimal fluctuations observed between grid number 113,273 and 227,478 for force computation. The computational time for the 113,273 grid was approximately 6 hours per results. With this information, the pre-setting on the number of grids required was developed to solve for GG and SG, consistently. 


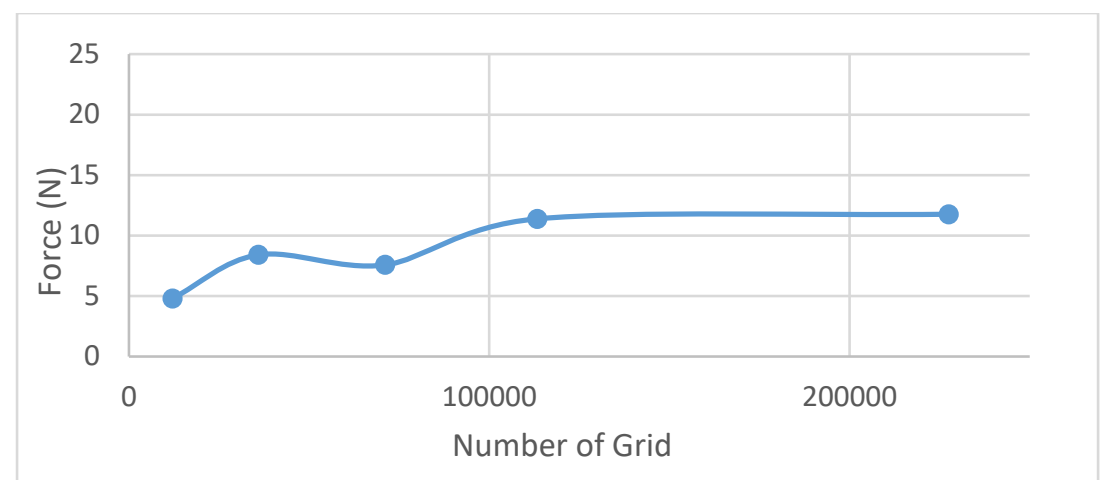

Fig. 9. Grid independent test (GIT) on force produced by number of grids up to 227,478 grids

\subsection{Total Tangential Forces (Z-axis) Produced at Different Turbine Orientations and Blade Angles}

In a mixed flow turbine, tangential velocity is one of the velocity components in water that can be extracted as energy and converted to mechanical energy [30]. A study by Sreerag et al., [25] had focused on maximizing the tangential components of flow in conical GWVT turbine setup by varying turbine geometry. Identifying tangential force (Z-axis) in a radial type turbine is crucial as it heavily contribute to torque produced at the shaft. In this study, the overall tangential force harnessed by the runner blade is denoted as force $Z$. For the selection of turbine orientation, comparison between similar setups of runner blade in vertical and horizontal orientation are observed to identify any fluctuations in performance between the two setups. On the other hand, in selecting runner blade angle, the design that is most suited for our enclosed GWVT is decided by identifying maximum tangential force able to be harnessed as the blade are gradually twisted in clockwise direction from $25^{\circ}$ to $120^{\circ}$.

Figure 10 shows force $Z$ produced using different blade angles in horizontal and vertical positions. Generally, the turbine orientation in both horizontal and vertical orientations produced very similar results in terms of force produced. However, the results show slight variation in force produced when using a $90^{\circ}$ runner blade in which the vertical orientation was able to extract more force compared to horizontal orientation. This vertical setup aligns the discharge side of the turbine with gravity which is also the case of the conventional GWVT turbine. The basis of vortex relies on the concentric flow from tangential entry of water which sees the velocity increases from low to high [39]. The vortex speed is highest in the middle section of the vortex [21]. By aligning the discharge with gravity, the turbine improves the discharge, thus producing better quality vortex which have contributed to a slight increase of $7.7 \%$ in vertical orientation.

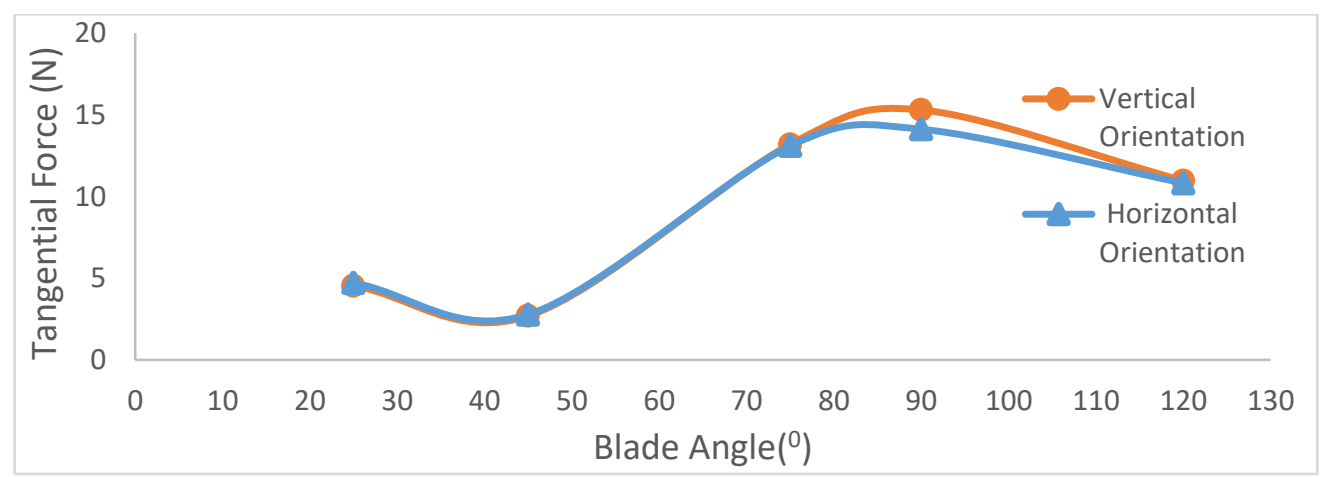

Fig. 10. Force $Z$ direction (tangential force) produced at different runner blade angle in vertical position and horizontal position 
The maximum force produced was found below $16 \mathrm{~N}$. It can be perceived that the highest force $Z$ produced is by utilising $90^{\circ}$ runner blade. Specifically, $15.31 \mathrm{~N}$ of force $Z$ was managed at vertical orientation and $14.13 \mathrm{~N}$ at horizontal orientation. The minor difference in force $Z$ produced gives insight of the capability for the enclosed GWVT to operate in two possible orientations (vertically and horizontally). The application of runner blade angles at $25^{\circ}$ and $45^{\circ}$ however are not feasible for enclosed GWVT turbine. These runner blades were not able to capture the concentric swirl velocity as they produced a very low force $Z$ in average of $4.5 \mathrm{~N}$ and $2.5 \mathrm{~N}$ for $25^{\circ}$ and $45^{\circ}$ runner blade angles, respectively. The contact between water flow and runner blade can be further studied from the cross section of velocity contour as shown in Figure 11 by dissecting the turbine at the runner blade portion.

We compared the turbine setup of minimum force $Z$ ( $45^{\circ}$ runner blade) and maximum force $Z$ $\left(90^{\circ}\right.$ runner blade) produced. Based on Figure 11 , it is apparent that the peak velocity produced is at inlet penstock which is $4.125 \mathrm{~m} / \mathrm{s}$. However, drop in velocity took place as the jet flow comes into contact with runner blade which is illustrated by the velocity contour on the backside of all 12 blades (faces not in contact with inlet jet). As shown in Figure 11(a), the backside of runner blades is flowing with velocity of $1.2 \mathrm{~m} / \mathrm{s}$ to $1.5 \mathrm{~m} / \mathrm{s}$ which in contrast to Figure $11(\mathrm{~b})$ where velocity flow after contact with runner blades is around $0.6 \mathrm{~m} / \mathrm{s}$ to $0.9 \mathrm{~m} / \mathrm{s}$. Based on that statement, we deduced that the $90^{\circ}$ runner blade angle was more befitting to be applied as the runner blade had channelled more energy from the incoming jet flow and produced highest force $Z$ of $15.31 \mathrm{~N}$ at vertical turbine orientation and $14.13 \mathrm{~N}$ at horizontal turbine orientation. The indication of successful energy transfer can be visualised by observing the transition of swirl flow to axial flow.

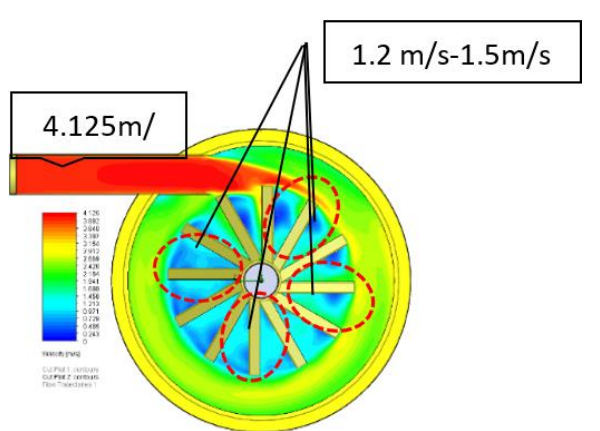

(a)

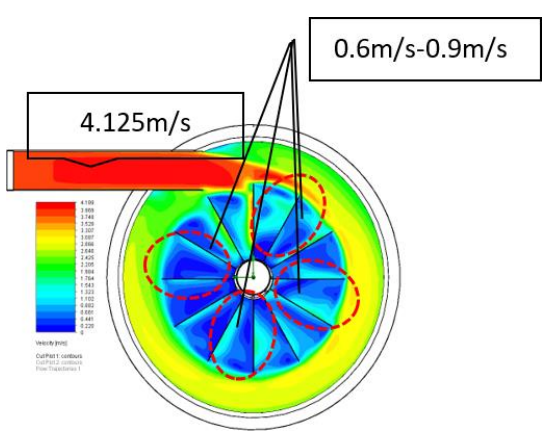

(b)

Fig. 11. Average velocity contour for a) runner blade of $45^{\circ}$ angle and b) runner blade of $90^{\circ}$ angle at vertical orientation

The flow trajectory using runner blade of $45^{\circ}$ angle also showed that more concentrated swirling trajectories were still being produced after in contact with flow. Also, the swirl remains after the runner blade is flowing at an average of $1.3 \mathrm{~m} / \mathrm{s}$, demonstrating available unextracted energy roughly $30 \%$ of peak jet flow velocity. Meanwhile, the flow trajectory after contact with $90^{\circ}$ angle runner blade showed more disrupted flow as it transitioned from swirl to axial flow at discharge point as seen from Figure 12. Nonetheless, there are still visible remains of swirl from using $90^{\circ}$ runner blade at an average of $0.6 \mathrm{~m} / \mathrm{s}$. Perhaps an additional runner blade can be suited in the region of the remaining swirl to fully extract the tangential force from the vortex swirl. The aid of visual understanding of flow trajectory allows us to better understand the vortex condition within the modified setup and is crucial for further development in future studies.

Other studies have also shown that using $90^{\circ}$ rectangular runner blades are more suitable in a GWVT setup with an average of $2 \%$ increment in efficiency compared to curved runner blades, nonetheless using cross-flow runner blades was the most efficient (6\% increment) [40]. 


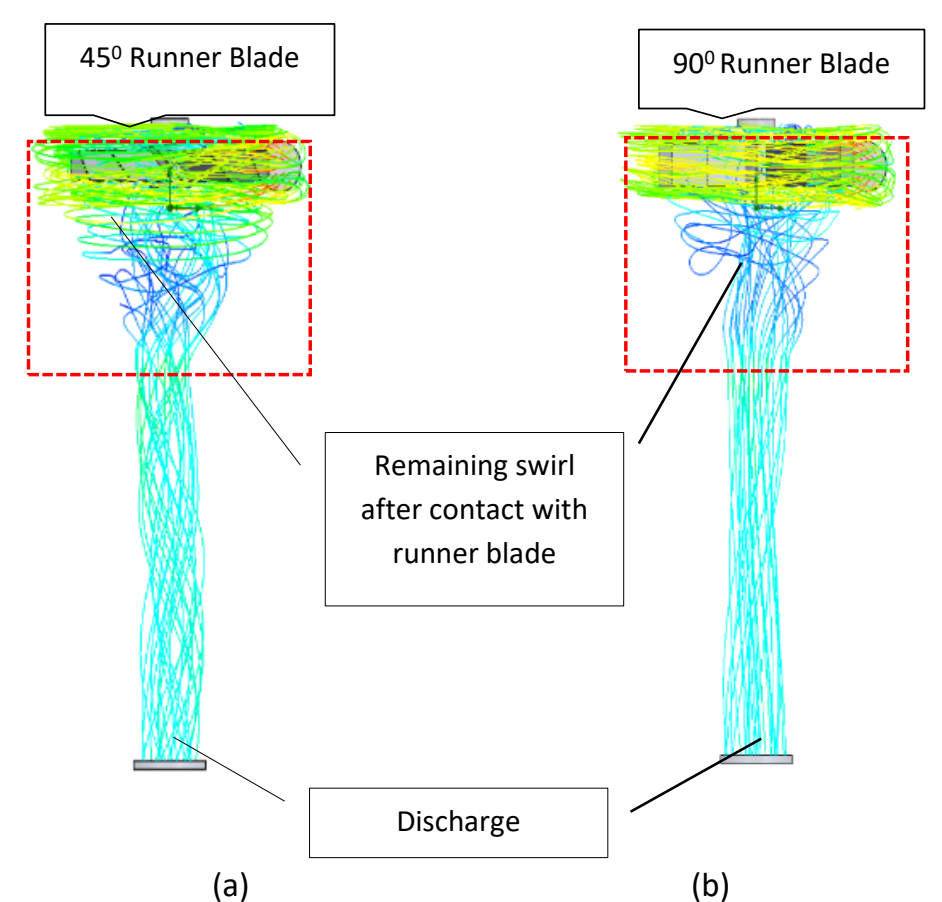

Fig. 12. Flow trajectory within enclosed GWVT when using a) $45^{\circ}$ runner blade and b) $90^{\circ}$ runner blade viewed from runner blade location to discharge

\subsection{Production of Forces Using Runner Blade of $90^{\circ}$ Angle at Different Blade Numbers}

Table 3 shows the tangential force (Z-axis) produced using different blade numbers for runner blade angled at $90^{\circ}$ in vertical orientation. Different numbers of blade were used i.e., 8, 12, and 18 . By reducing the number of blades from 12 to 8 , there was a drop in tangential force produced by $1.12 \mathrm{~N}$ (7.3\% drop). As seen in Figure 13, using smaller amount of blade numbers creates more gap between blades thus allowing more water to be in contact with it, but 8 blades are not sufficient enough to capture the overall swirl produced by the incoming flow. By increasing the number of blades from 12 to 18 there was also a drop in tangential force produced by $3.04 \mathrm{~N}$ (19.85\% drop). With too many numbers of blade, the gap between the blades is too small thus water cannot provide sufficient contact to the blades as seen in Figure 13.

\section{Table 3}

Tangential force produced using different blade numbers for $90^{\circ}$ blade angle in vertical orientation

\begin{tabular}{llll}
\hline Force $(\mathrm{N})$ & \multicolumn{4}{l}{ Blade Numbers } \\
& 8 & 12 & 18 \\
\hline Force (Z-axis) & $14.19 \mathrm{~N}$ & $15.31 \mathrm{~N}$ & $12.27 \mathrm{~N}$ \\
\hline
\end{tabular}

Based on these findings, 12 blades were the most suitable number for this type of turbine as it can produce the highest overall force and tangential force between them. Using 12 blades produces more effective gaps to harness flow without compromising surface area of contact. By maximising the surface area of contact, more energy can be harnessed. 


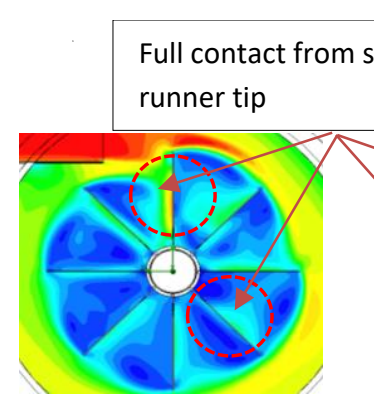

(a)

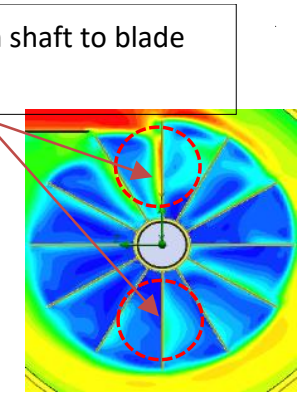

(b)

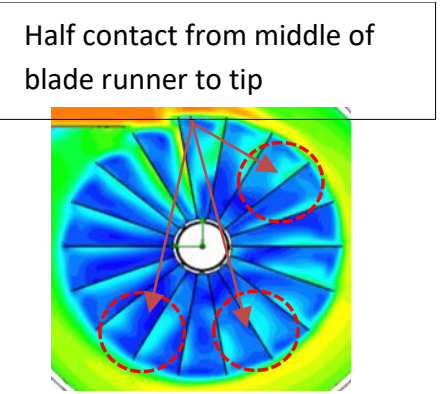

(c)

Fig. 13. Velocity contour of a) 8 blades, b) 12 blades and c) 18 blades using runner blade of $90^{\circ}$ angle

A similar study but using conventional GWVT deduced that the number of runner blade found to be optimum was 4 , nonetheless the study had only compared between using 2 runner blades and 4 runner blades as the focused parameter was more on flow head [21].

In contrast to conventional conical GWVT, there are obvious potentials in using enclosed GWVT instead of open GWVT (free surface flow) as the numerical simulation results show a comparable tangential force able to be extracted. In terms of turbine orientation, vertical turbine setup had always been the concept of application in conventional GWVT as reviewed by Timilsina et al., [41], suggesting that majority of GWVT in her literature was GWVT in upright position with $54 \%$ average efficiency. While the study from Zarate-Orrego et al., [35] operated a horizontal vortex chamber while being fully submerged in water flow. However, our study points out the flexibility of implementation using enclosed GWVT as it is able to operate in both vertical and horizontal orientations without submergence.

\section{Conclusion}

Simulation of conical GWVT was designed and studied using SOLIDWORKS 2018 flow simulation, aimed to harness force from the enclosed system as reaction turbine. The water flow rate was constant at $0.01 \mathrm{~m}^{3} / \mathrm{s}$ and the turbine geometry specifications were fixed. Two different turbine orientations were simulated e.g., vertical and horizontal at different runner blade angles i.e., $25^{\circ}, 45^{\circ}$, $75^{\circ}, 90^{\circ}$, and $120^{\circ}$ and force were harnessed at tangential direction (Z-axis) using 12 blades. Optimum force produced at the best orientation and blade angle was then further simulated using different number of blades i.e., 8 and 18. The simulation results showed that it was possible to run and produce the forces from modified GWVT turbine design in an enclosed system. It was also found that vertical turbine orientation with $90^{\circ}$ angled runner blade produced slightly higher force than horizontal orientation at the same blade angle where the forces found were $15.31 \mathrm{~N}$ and $14.12 \mathrm{~N}$ respectively, at tangential (Z-axis) direction. Nevertheless, both turbine orientations can still be recommended for this turbine design as both turbines were able to produce force on runner blade without any major drop in the force produced. Although the analysis was further simulated using different number of blades at 8 and 18, the force produced at tangential forces (Z-axis) for vertical orientation were $14.19 \mathrm{~N}$ and $12.27 \mathrm{~N}$ which were lower than the force produced using 12 blades, hence 12 blades still produced the optimum force $(15.31 \mathrm{~N})$. The results are useful to calculate actual torque produced prior to actual conical GWVT setup to minimise cost implication and construction issues. It is recommended that in the future study, cavitation should be considered in the analysis as it also affects the overall performance for better long-term life cycle. 


\section{Acknowledgments}

The authors acknowledge the Faculty of Chemical Engineering, College of Engineering, Universiti Teknologi MARA (UiTM) Sarawak Branch, Samarahan Campus and Stoma Sdn Bhd, Kuching Sarawak for the analytical laboratory and excellent technical support towards this research. This research did not receive any specific grant from funding agencies in the public, commercial, or not-for-profit sectors.

\section{References}

[1] Azam, Muhammad. "Energy and economic growth in developing Asian economies." Journal of the Asia Pacific Economy 25, no. 3 (2020): 447-471. https://doi.org/10.1080/13547860.2019.1665328

[2] Haiges, Rina, Y. D. Wang, A. Ghoshray, and A. P. Roskilly. "Optimization of Malaysia's power generation mix to meet the electricity demand by 2050." Energy Procedia $142 \quad$ (2017): 2844-2851. https://doi.org/10.1016/i.egypro.2017.12.431

[3] Oh, Tick Hui, Md Hasanuzzaman, Jeyraj Selvaraj, Siew Chein Teo, and Shing Chyi Chua. "Energy policy and alternative energy in Malaysia: Issues and challenges for sustainable growth-An update." Renewable and Sustainable Energy Reviews 81 (2018): 3021-3031. https://doi.org/10.1016/j.rser.2017.06.112

[4] Khamis, Aziah, Tamer Khatib, Nur Amira Haziqah Mohd Yosliza, and Aimie Nazmin Azmi. "Optimal selection of renewable energy installation site in remote areas using segmentation and regional technique: $A$ case study of Sarawak, Malaysia." Sustainable Energy Technologies and Assessments 42 (2020): 100858. https://doi.org/10.1016/i.seta.2020.100858

[5] Borhanazad, H., S. Mekhilef, R. Saidur, and G. Boroumandjazi. "Potential application of renewable energy for rural electrification in Malaysia." Renewable Energy 59 (2013): 210-219. https://doi.org/10.1016/i.renene.2013.03.039

[6] Mahmud, Abdul Muhaimin. "Evaluation of the Solar Hybrid System for Rural Schools in Sabah; Malaysia." In World Renewable Energy Congress-Sweden; 8-13 May; 2011; Linköping; Sweden, no. 057, pp. 2977-2984. Linköping University Electronic Press, 2011. https://doi.org/10.3384/ecp110572977

[7] DOS Malaysia. "The Source of Malaysia's Official Statistics: Sarawak." Department of Statistics Malaysia Official Portal, $\quad$ August 20, 2021. https://www.dosm.gov.my/v1/index.php?r=column/cone\&menu id=clJnWTITbWFHdmUwbmtSTE1EQStFZz09\#.

[8] Khengwee, Tan, P. R. P. Hoole, K. Pirapaharan, Norhuzaimin Julai, Al-Khalid Hj Othman, Martin Anyi, Ahmed MA Haidar, and S. R. H. Hoole. "A review of sarawak off-grid renewable energy potential and challenges." Journal of Telecommunication, Electronic and Computer Engineering (JTEC) 9, no. 3-10 (2017): 29-33.

[9] Chachuli, Fairuz Suzana Mohd, Sohif Mat, Norasikin Ahmad Ludin, and Kamaruzzaman Sopian. "Performance evaluation of renewable energy R\&D activities in Malaysia." Renewable Energy 163 (2021): 544-560. https://doi.org/10.1016/j.renene.2020.08.160

[10] Hossain, Farhad M., Mohammad Hasanuzzaman, N. A. Rahim, and H. W. Ping. "Impact of renewable energy on rural electrification in Malaysia: a review." Clean Technologies and Environmental Policy 17, no. 4 (2015): 859-871. https://doi.org/10.1007/s10098-014-0861-1

[11] Van Gevelt, T., T. Zaman, F. George, M. M. Bennett, S. D. Fam, and J. E. Kim. "End-user perceptions of success and failure: Narratives from a natural laboratory of rural electrification projects in Malaysian Borneo." Energy for Sustainable Development 59 (2020): 189-198. https://doi.org/10.1016/i.esd.2020.10.008

[12] Shahzad, Umair. "The need for renewable energy sources." International Journal of Information Technology and Electrical Engineering 2 (2012): 16-18.

[13] Shekarchian, M., Mahmoud Moghavvemi, T. M. I. Mahlia, and A. Mazandarani. "A review on the pattern of electricity generation and emission in Malaysia from 1976 to 2008." Renewable and Sustainable Energy Reviews 15, no. 6 (2011): 2629-2642. https://doi.org/10.1016/i.rser.2011.03.024

[14] Mohd, Shabdin, Norliana Mohd, and Cheng Ann Chen. Free-living Nematodes in Sarawak Coastal Waters. Universiti Malaysia Terengganu, 2013.

[15] Hussein, Ibrahim, and Nathan Raman. "Reconnaissance studies of micro hydro potential in Malaysia." In Proceedings of the International Conference on Energy and Sustainable Development: Issues and Strategies (ESD 2010), pp. 1-10. IEEE, 2010. https://doi.org/10.1109/ESD.2010.5598802

[16] Nazari-Heris, Morteza, and Behnam Mohammadi-Ivatloo. "Design of small hydro generation systems." Distributed Generation Systems (2017): 301-332. https://doi.org/10.1016/B978-0-12-804208-3.00006-6

[17] Yaakob, O. B., Yasser M. Ahmed, A. H. Elbatran, and H. M. Shabara. "A review on micro hydro gravitational vortex power and turbine systems." Jurnal Teknologi 69, no. 7 (2014): 1-7. https://doi.org/10.11113/jt.v69.3259 
[18] Elbatran, A. H., O. B. Yaakob, Yasser M. Ahmed, and H. M. Shabara. "Operation, performance and economic analysis of low head micro-hydropower turbines for rural and remote areas: A review." Renewable and Sustainable Energy Reviews 43 (2015): 40-50. https://doi.org/10.1016/j.rser.2014.11.045

[19] Andritz. "ANDRITZ Financial Report 2018." ANDRITZ AG, Austria (2018). https://www.andritz.com/resource/blob/290372/21569dd68b1a08ccfe652ce496bb2b5a/andritz-financialreport-2018-e-data.pdf.

[20] Jha, Ajay Kumar, Deepa Upadhyaya Subedi, and Ashesh Babu Timilsina. "Assessment of Gravitational Water Vortex Hydropower Plant in Nepal." International Research Journal of Engineering and Technology 5, no. 7 (2018): 26792691.

[21] Power, Christine, Aonghus McNabola, and Paul Coughlan. "A Parametric Experimental Investigation of the Operating Conditions of Gravitational Vortex Hydropower (GVHP)." Journal of Clean Energy Technologies 4, no. 2 (2016): 112-119. https://doi.org/10.7763/JOCET.2016.V4.263

[22] Rahman, M. M., J. H. Tan, M. T. Fadzlita, and A. R. Wan Khairul Muzammil. "A Review on the development of Gravitational Water Vortex Power Plant as alternative renewable energy resources." In IOP Conference Series: Materials Science and Engineering, vol. 217, no. 1, p. 012007. IOP Publishing, 2017. https://doi.org/10.1088/1757899X/217/1/012007

[23] Kueh, Tze Cheng, Shiao Lin Beh, Dirk Rilling, and Yongson Ooi. "Numerical analysis of water vortex formation for the water vortex power plant." International Journal of Innovation, Management and Technology 5, no. 2 (2014): 111-115.

[24] lemsomboon, Pimnapat, Trirath Pati, and Krischonme Bhumkittipich. "Performance study of micro hydro turbine and PV for electricity generator, case study: Bunnasopit school, Nan Province, Thailand." Energy Procedia 34 (2013): 235-242. https://doi.org/10.1016/i.egypro.2013.06.752

[25] Sreerag, S. R., C. K. Raveendran, and B. S. Jinshah. "Effect of outlet diameter on the performance of gravitational vortex turbine with conical basin." International Journal of Scientific \& Engineering Research 7, no. 4 (2016): $457-$ 463.

[26] Adhikari, Ram, and David Wood. "The design of high efficiency crossflow hydro turbines: A review and extension." Energies 11, no. 2 (2018): 267. https://doi.org/10.3390/en11020267

[27] Khosrowpanah, Shahram, A. A. Fiuzat, and Maurice L. Albertson. "Experimental study of cross-flow turbine." Journal of Hydraulic Engineering 114, no. 3 (1988): 299-314. https://doi.org/10.1061/(ASCE)07339429(1988)114:3(299)

[28] Singh, Punit, and Franz Nestmann. "Experimental investigation of the influence of blade height and blade number on the performance of low head axial flow turbines." Renewable Energy 36, no. 1 (2011): $272-281$. https://doi.org/10.1016/j.renene.2010.06.033

[29] Sritram, P., and R. Suntivarakorn. "The effects of blade number and turbine baffle plates on the efficiency of freevortex water turbines." In IOP Conference Series: Earth and Environmental Science, vol. 257, no. 1, p. 012040. IOP Publishing, 2019. https://doi.org/10.1088/1755-1315/257/1/012040

[30] Breeze, Paul. Hydropower. Academic Press, 2018. https://doi.org/10.1016/B978-0-12-812906-7.00006-5

[31] Teresa, T., G. G. Visal, P. Sai Ram, and M. Srimani Kumar. "Experimental analysis on francis turbine at full load to determine the performance characteristics curves." International Journal of Mechanical Engineering and Technology 9, no. 2 (2018): 663-669.

[32] Ullah, Rizwan, Taqi Ahmad Cheema, Abdul Samad Saleem, Sarvat Mushtaq Ahmad, Javed Ahmad Chattha, and Cheol Woo Park. "Preliminary experimental study on multi-stage gravitational water vortex turbine in a conical basin." Renewable Energy 145 (2020): 2516-2529. https://doi.org/10.1016/i.renene.2019.07.128

[33] Sritram, Piyawat, and Ratchaphon Suntivarakorn. "Comparative study of small hydropower turbine efficiency at low head water." Energy Procedia 138 (2017): 646-650. https://doi.org/10.1016/i.egypro.2017.10.181

[34] Dhakal, Sagar, Ashesh B. Timilsina, Rabin Dhakal, Dinesh Fuyal, Tri R. Bajracharya, Hari P. Pandit, Nagendra Amatya, and Amrit M. Nakarmi. "Comparison of cylindrical and conical basins with optimum position of runner: Gravitational water vortex power plant." Renewable and Sustainable Energy Reviews 48 (2015): 662-669. https://doi.org/10.1016/i.rser.2015.04.030

[35] Zarate-Orrego, Sergio Antonio, Gerardo Andrés Torres-Casierra, and Efraín Baldemar del Risco-Moreno. "Horizontal vortex single chamber hydroturbine." Revista Facultad de Ingeniería Universidad de Antioquia 79 (2016): $150-162$. https://doi.org/10.17533/udea.redin.n79a14

[36] Versteeg, Henk Kaarle, and Weeratunge Malalasekera. An introduction to computational fluid dynamics: the finite volume method. Pearson Education, 2007.

[37] Sobachkin, A., and G. Dumnov. "Numerical basis of CAD-embedded CFD." In NAFEMS World Congress, pp. 9-12. 2013. 
[38] Ebhota, Williams S., and Freddie Inambao. "Design basics of a small hydro turbine plant for capacity building in subSaharan Africa." African Journal of Science, Technology, Innovation and Development 8, no. 1 (2016): 111-120. https://doi.org/10.1080/20421338.2015.1128039

[39] Wanchat, Sujate, and Ratchaphon Suntivarakorn. "Preliminary design of a vortex pool for electrical generation." Advanced Science Letters 13, no. 1 (2012): 173-177. https://doi.org/10.1166/asl.2012.3855

[40] Khan, Nauman Hanif, Taqi Ahmad Cheema, Javed Ahmad Chattha, and Cheol Woo Park. "Effective basin-blade configurations of a gravitational water vortex turbine for microhydropower generation." Journal of Energy Engineering 144, no. 4 (2018): 04018042. https://doi.org/10.1061/(ASCE)EY.1943-7897.0000558

[41] Timilsina, Ashesh Babu, Sean Mulligan, and Tri Ratna Bajracharya. "Water vortex hydropower technology: a stateof-the-art review of developmental trends." Clean Technologies and Environmental Policy 20, no. 8 (2018): 17371760. https://doi.org/10.1007/s10098-018-1589-0 